\title{
Patient satisfaction with Locator-retained overdentures
}

\author{
Christos Alamanos $^{\text {1*}}$, Matthias Stöckle ${ }^{1}$, Martin Rosentritt ${ }^{1}$ and Sebastian Hahnel ${ }^{2}$ \\ ${ }^{1}$ Department of Prosthetic Dentistry, Regensburg University Medical Center, Regensburg, Germany \\ ${ }^{2}$ Department of Prosthetic Dentistry, University of Leipzig Medical Center, Leipzig, Germany
}

\begin{abstract}
Purpose: This study aimed to investigate satisfaction of patients supplied with mandibular Locator-retained implant-supported overdenture (IODs).

Material and Methods: 15 patients that had been supplied with mandibular Locator-retained IODs were invited to complete a questionnaire tailored for investigating satisfaction with their Locator-retained IOD.

Results: Patient satisfaction with Locator-retained IODs was high, although loss of retention was regularly observed by many patients and costs for exchange of the nylon inserts were regarded as too high.

Conclusion: Despite of regular and repeated maintenance requirements, patients supplied with mandibular Locator-retained IODs are very satisfied with this prosthetic concept.
\end{abstract}

\begin{abstract}
Abbreviation: IOD-Implant overdenture.
\section{Introduction}

The Locator $^{\odot}$-retained implant overdenture (IOD) has been introduced as a modern minimum standard of care concept for the rehabilitation of the edentulous mandible, requiring a minimum of two implants $[1,2]$. The Locator ${ }^{\odot}$ system features several advantages such as angulation versatility, pivoting action of the metal housings over the male inserts, low vertical profile, and self-aligning design; moreover, insertion of the IOD is simple and does not require specific manual skills, which makes the Locator system a favorable choice for application in implant-supported removable restorations in elderly patients. Previous studies have highlighted that patients supplied with Locator-retained IODs have a higher oral health-related quality of life than patients with complete dentures [3-5]; however, it has also been underlined that the retention of Locator-supported IODs decreases significantly with time and regular maintenance is necessary [6,7]. Regarding patient satisfaction with Locator-supported IODs, most previous studies focused on the investigation of oral health-related quality of life; thus, the aim of the current study was to evaluate patient satisfaction with Locator-retained mandibular IODs using a questionnaire targeting on issues that are particularly associated with the application of the Locator attachment system. It was hypothesized that patient satisfaction is low due the regular maintenance requirements.
\end{abstract}

\section{Material and methods}

A total of 42 patients that had been supplied with IODs retained

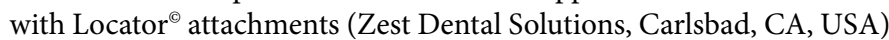
in the Department of Prosthetic Dentistry at the Regensburg University Medical Center, Germany, between 2008 and 2016 were invited to participate in a survey on satisfaction with their Locator-retained IOD. 15 patients that had been supplied with mandibular IODs agreed to complete a questionnaire designed for specifics of Locator-retained IODs (Table 1-2) and to rate their denture in accordance with the German school grade system (1: very good, 6: insufficient). The study was performed in accordance with the 1964 Helsinki declaration and its later amendments and approved by the local ethics committee (approval number: 16-101-0060). All patients gave their informed consent to participate. Means and standard deviations for patient data and frequencies for the different items of the questionnaire were calculated (IBM SPSS Statistics Version 21.0, IBM, Armonk, USA).

\section{Results}

15 patients ( 8 male, 7 female) with a mean age of $67.5( \pm 11.1)$ years completed the questionnaire; the mandibular IODs in these patients were in clinical service for a mean time of $6.2( \pm 3.1)$ years. 14 patients were supplied with two implants, while one patient had a single implant; the antagonistic dentition was either fixed $(N=1)$ or removable $(N=14)$, including clasp- $(N=1)$, double crown- $(N=1)$ and implant-retained dentures $(N=2)$ or complete dentures $(N=10)$.

Tables 1 and 2 illustrate the results of the questionnaire. More than $86 \%$ of the patients rated their denture very good $(N=3)$, good $(N=5)$, or satisfying $(N=5)$; two patients rated their denture fair $(N=1)$ or poor $(N=1)$; this rating responds to the degrees of satisfaction with denture comfort and retention and the high percentage of interviewed patients who would recommend Locator-retained IODs. The majority of interviewed patients affirmed that they were not restricted regarding their chewing ability or the type of food, although more than $45 \%$ reported that they cannot bite an apple. More than $90 \%$ of the interviewed patients appreciated the ease of cleaning of the Locator abutments. At least one third of the interviewed patients complained

${ }^{\star}$ Correspondence to: Christos Alamanos, DDS, MSc, Department of Prosthetic Dentistry, Regensburg University Medical Center, 93053 Regensburg, Germany, E-mail: christos.alamanos@ukr.de

Key words: humans, denture overlay, patient satisfaction

Received: August 15, 2018; Accepted: August 24, 2018; Published: August 27, 2018 
Table 1. Frequencies of responses to the various items of the questionnaire to investigate denture satisfaction (Part I, trichotomous questions)

\begin{tabular}{|c|c|c|c|}
\hline & I agree. & I do not agree. & I do not know. \\
\hline I can bite like I used to with my natural teeth. & $73.3 \%$ & $20.0 \%$ & $6.7 \%$ \\
\hline I have no pain in the area of the implants. & $86.7 \%$ & $13.3 \%$ & - \\
\hline I do not have to abstain from certain food. & $66.7 \%$ & $33.3 \%$ & - \\
\hline I can bite an apple. & $40.0 \%$ & $46.7 \%$ & $13.3 \%$ \\
\hline Cleaning of the Locator abutments is easy and convenient. & $93.3 \%$ & $6.7 \%$ & - \\
\hline I can chew without restrictions. & $60.0 \%$ & $40.0 \%$ & - \\
\hline The mandibular denture moves easily. & $60.0 \%$ & $40.0 \%$ & - \\
\hline Food debris under the mandibular denture disturbs after eating.* & $80.0 \%$ & $13.3 \%$ & - \\
\hline Due to the mandibular denture I cannot speak adequately. & $6.7 \%$ & $93.3 \%$ & - \\
\hline Retention of the implant-supported mandibular denture decreases quickly. & $33.3 \%$ & $53.3 \%$ & $13.3 \%$ \\
\hline Exchange of the retention inserts improves retention significantly. & $80.0 \%$ & $6.7 \%$ & $13.3 \%$ \\
\hline Exchange of the retention inserts is too expensive. & $66.7 \%$ & $6.7 \%$ & $26.7 \%$ \\
\hline I recommend Locator-supported implant-retained overdentures. & $73.3 \%$ & $13.3 \%$ & $13.3 \%$ \\
\hline
\end{tabular}

Table 2. Frequencies of responses to the various items of the questionnaire to investigate denture satisfaction (Part II, multiple responses possible)

\begin{tabular}{|c|c|c|c|c|c|}
\hline & Very satisfied & Satisfied & Average & Unsatisfied & Very unsatisfied \\
\hline How satisfied are you with the comfort of your mandibular denture? & $33.3 \%$ & $33.3 \%$ & $26.7 \%$ & $6.7 \%$ & - \\
\hline How satisfied are you with the retention of your mandibular denture? & $26.7 \%$ & $33.3 \%$ & $26.7 \%$ & $13.3 \%$ & - \\
\hline
\end{tabular}

about a rapid decrease of retention, and yet $80 \%$ affirmed that exchange of the nylon inserts significantly increases retention. Two thirds rated costs for the exchange of the inserts as too high.

\section{Discussion}

The results of the current study suggest that patients supplied with Locator-retained mandibular IODs have a high degree of satisfaction with this attachment system; thus, the study hypothesis has to be rejected. These results support previous studies proving an increase in the oral health-related quality of life in patients supplied with Locatorsupported IODs and underline the suitability of Locator-supported IODs as a minimum standard of care concept in edentulous patients. Easy cleansability - which was highly appreciated by the interviewed patients in the current investigation - features another advantage of the attachment system for use in geriatric patients. Some researchers have addressed that Locator attachments require fewer maintenance than other attachment systems [8], while other researchers accentuated that the attachment system requires regular and frequent maintenance as a result of deterioration of the nylon inserts and wear of the Locator abutments [6,7]. With regard to this aspect, maintenance requirements and costs have also been a relevant issue for the patients interviewed in the current study. As the majority of interviewed patients rated the costs for exchange of the nylon inserts as too high, this issue should be well addressed prior to treatment.

\section{Conclusion}

This study investigated patient satisfaction in relation to Locatorsupported IODs with the help of patient questionnaires. In our group, overall satisfaction remained very high despite the high maintenance requirements of this treatment modality.

\section{References}

1. Feine JS, Carlsson GE, Awad MA, Chehade A, Duncan WJ, et al. (2002) The McGill consensus statement on overdentures. Mandibular two-implant overdentures as first choice standard of care for edentulous patients. Gerodontology 19: 3-4. [Crossref]

2. Thomason JM, Feine J, Exley C, Moynihan P, Müller F, et al. (2009) Mandibular two implant-supported overdentures as the first choice standard of care for edentulous patients--the York Consensus Statement. Br Dent J 207: 185-186. [Crossref]

3. Karbach J, Hartmann S, Jahn-Eimermacher A, Wagner W (2015) Oral Health-Related Quality of Life in Edentulous Patients with Two- vs Four-Locator-Retained Mandibula Overdentures: A Prospective, Randomized, Crossover Study. Int J Oral Maxillofac Implants 30: 1143-1148. [Crossref]

4. Fernandez-Estevan L, Selva-Otaolaurruchi EJ, Montero J, Sola-Ruiz F (2015) Oral health-related quality of life of implant-supported overdentures versus conventional complete prostheses: Retrospective study of a cohort of edentulous patients. Med Oral Patol Oral Cir Bucal 20: e450-8. [Crossref]

5. Khalid T, Yunus N, Ibrahim N, Elkezza A, Masood M (2017) Patient-reported outcome and its association with attachment type and bone volume in mandibular implant overdenture. Clin Oral Implants Res 28: 535-542. [Crossref]

6. Engelhardt F, Zeman F, Behr M, Hahmel S (2016) Prosthetic Complications and Maintenance Requirements in Locator-attached Implant-Supported Overdentures: A Retrospective Study. Eur J Prosthodont Restor Dent 24: 31-35. [Crossref]

7. Hahnel S, Alamanos C, Schneider-Feyrer S, Stöckle M, Rosentritt M (2017) Investigation of clinical and laboratory wear in Locator-supported implant-retained overdentures. Int J Prosthodont 31: 334-337. [Crossref]

8. Cristache CM, Muntianu LAS, Burlibasa M, Didilescu AC (2014) Five-year clinical trial using three attachment systems for implant overdentures. Clin Oral Implants Res 25: e171-8. [Crossref]

Copyright: (2018 Alamanos C. This is an open-access article distributed under the terms of the Creative Commons Attribution License, which permits unrestricted use, distribution, and reproduction in any medium, provided the original author and source are credited. 